Jorge Edwards: El Inútil de la Familia

(Alfaguara, 2004).

\title{
AUSENCIA DE JOAQUÍN
}

\section{Mario Valdovinos}

Es un relato de huesos heridos, amargas circunstancias e interminables trajes...

(Pablo Neruda. "Desespediente”.)

\section{Viajes con mi tío}

$\mathrm{E}$ n medio de la gran cantidad de fantasmas de carne y hueso aparecidos en las novelas, cuentos y crónicas de Jorge Edwards, había uno que era insoslayable y, tarde o temprano, debía tomar cuerpo. Se trata de Joaquín Edwards Bello, su tío, el inútil de Joaquín, como le advertían al sobrino, incipiente escritor, previniéndole sobre una vida de bohemio y tarambana, el destino de un perdido.

El Inútil de la Familia se llama la novela que acaba de publicar Jorge Edwards (Editorial Alfaguara, octubre de 2004), basada en esta figura polémica y fascinante. En ella el sobrino define al tío Joaquín como un autor rocambolesco, puesto que las aventuras de Rocambole eran una de sus lecturas preferidas, además de escritor incorrecto, proclive a los desbordes y poco ajustado a los cánones y normas que caracterizan a los géneros. Si

MARio VALDovinos. Escritor y profesor de literatura y cine en el colegio The Grange (Santiago). 
escribía una novela divagaba demasiado en el interior de su trama, diluyéndola; si redactaba una crónica incluía en su elaboración elementos ficticios, inaceptable; si elaboraba un ensayo de tono político, en algunos párrafos levitaba a la manera de un poeta lírico, entonces, poco riguroso; en suma, no se ajustaba a las rigideces genéricas e intentaba, de modo consciente o no, subvertirlos, mezclarlos, borrar sus fronteras y sus límites.

Todo un adelantado a las tendencias actuales.

En los aspectos propios de su compleja personalidad, el sobrino en segundo grado, Jorge, muestra a su tío como un vividor desaforado, un ser en conflicto con todo cuanto lo rodeaba, en primer lugar con su clase, ya que era bisnieto de don Andrés Bello, el ilustre sabio venezolano, primer rector de la Universidad de Chile, el bisabuelo pétreo como él lo llamó, vigilando desde su estatua de mármol a la entrada de la universidad. Joaquín despreció a la aristocracia, a su conservadurismo, a su doble estándar, al poder político reaccionario, al espíritu de clan, a los privilegios económicos, a la desigualdad en las oportunidades educacionales, pero en especial vivió en desacuerdo consigo mismo, se sentía incómodo con él, esta dislocación se va haciendo más evidente en la madurez, con su cuerpo, con su alma, con su pasado y, por supuesto, con su presente, transformándose en los devaneos y locuras de un escriba, un bueno para nada, un patán ilustrado.

Por otra parte, Jorge Edwards lo pinta como un timbero, un ludópata capaz de jugarse al doble o nada los escasos bienes que le iban quedando, ya fuese en un casino, en un garito ilegal o en un hipódromo, la pasión y el vértigo de los dados, los caballos y los naipes lo asediaron desde siempre. También aparece como un Tenorio, que podía ser el enamorado de una muchacha parisina, tan atractiva como pajarona, y el babeante minotauro que merodeaba por arrabales, desesperado por meretrices de nalgas y senos voluminosos, con quienes consuma citas galantes en la Ciudad Luz o en un degradado barrio santiaguino, coitos fugaces, al paso, al borde del abismo, tras una noche de derrota en la ruleta. Se vuelve el protagonista de novelas galantes, un dandy de la gloria y de la miseria que después de recorrer el mundo y alojar en hoteles espléndidos de Europa, termina su existencia viviendo de sus olvidos en el abismo de una vieja casa de Santo Domingo abajo, en la que no recibe a nadie que no conozca un estricto código de ingreso. De hecho, ya le sobrevino la trombosis que le dejó un lado del cuerpo semiparalizado y un sector de su cara y de su boca recogidos en una mueca grotesca de hombre que ríe a su pesar; por tanto, si llega a darse el caso de que él deba abrir la puerta de entrada ante los timbrazos insistentes, porque su mujer, la Mayita, no está o está muy ocupada en los quehaceres 
domésticos, Joaquín acude al umbral de su mansión de Usher provisto de una máscara de goma, un disfraz facial carnavalesco, y con voz de actor se niega a sí mismo, diciendo con un tono inapelable que el señor no está, anda de veraneo en Zapallar o partió hace tres días a París, como corresponsal de un diario o revista ilusorios, en último término, ya no vive aquí.

Se vuelve así su propio sosías, su negación, el embozado que huye de la luz, de los espejos, y reside en su estudio, en la penumbra, al fondo de su última morada, donde no llegan los gritos de los niños del barrio, las peleas de los gatos, los ladridos de los perros, los quejidos de los parientes enfermos ni los bocinazos de los automóviles que transitan por la calle, por Santo Domingo, hacia el poniente, hacia la Quinta Normal, hacia el océano. ¿También se volvió ése, con los años, uno de los tantos lugares de mala muerte que conoció? Allí escribe sus crónicas, no para El Mercurio, obvio, sino para La Nación, que dirige Eliodoro Yáñez. Lo hace durante medio siglo, no puede dejar de hacerlo, aunque las ama y las odia, dice que se amarillean doce horas después de publicadas y mueren con el crepúsculo, al día siguiente pueden encontrarse en el portal de una casa para limpiarse los pies del barro, en una tarde de lluvia.

No sabe aún que otro escritor, obseso como él, las lee y las colecciona, años después le pedirá una entrevista para lograr su autorización y publicarlas en varios volúmenes. Es Alfonso Calderón, un discípulo, tan memorioso como Joaquín.

Como si esto fuera poco, el sobrino lejano, Jorge, examina al tío indescifrable en su condición de libertino, de desclasado, además de su identidad de gran señor y rajadiablos. Es un rebelde, un escritor maldito de esos que brillan millares de años y que muy pocos ven, creadores que emiten relámpagos en la penumbra, una zona que les acomoda y a la que al mismo tiempo desprecian y temen, mirándose con distancia e ironía, autosabotéandose a cada paso, un botarate de su talento, un dispendioso, un derrochador de vida, fuera de ser un romántico; en definitiva, un solitario.

¿Podemos afirmar que El Inútil de la Familia es una novela?; ¿̇o se trata de un reportaje, de una biografía a cuatro manos, o quizás no es otra cosa que un informe familiar?; ¿tal vez un ajuste de cuentas con una sombra de la atroz parentela? Probablemente todo eso, un texto que reafirma, pero al mismo tiempo quiebra una vez más, desde otra orilla, la noción de novela, un escrito de corte testamentario redactado a través de años por el sobrino Jorge para exorcizar al fantasma del pariente loco, de atar, de patio, el chalado Joaquín, esa sombra inquieta que lo seguía en un comienzo con cierto pudor y distancia, cuando el sobrino era un niño estudiante, por los patios conventuales del colegio San Ignacio, de Alonso Ovalle, después con algo 
más de énfasis por las aulas de la Escuela de Derecho de la Universidad de Chile y, en último término, por medio de una persecución explícita, parecida a un viaje, a una travesía llena de trampas y obstáculos, en la que, sin embargo, los roles de quien huye y de quien acecha se invierten; un espectro infiltrado en las páginas de la primera novela de Jorge El Peso de la Noche, deslizándose movedizo y ubicuo en sus argumentos, en sus incertidumbres, en sus deseos, tal vez sin que ni perseguidor ni perseguido lo buscaran, ya que estos términos son, en el caso de tío y sobrino, perfectamente intercambiables.

\section{Propuesta narrativa}

Lo que sí podemos afirmar es que se trata, sin mayores balbuceos, de un relato literario que contiene elementos propios de la biografía y de la autobiografía, y se basa, cómo no, en el rescate del pasado, en el mundo de la memoria, “esa vieja ciudad de traiciones”, como la define Jorge Edwards en el prólogo de la Antología de Familia (Editorial Sudamericana, octubre de 2002), que recoge una selección de crónicas y capítulos de novelas escritos por Edwards Bello. La memoria y la nostalgia, tal vez la sal y el agua de sus días sin objeto, como señala Jorge Teillier en su poema "Despedida", otra silueta que merodea en la historia real del tío escribidor. Algo semejante ocurre con la de Enrique Lihn.

El punto de vista narrativo es el de una figura fuertemente personal, divagante, movediza, ágil, a la manera del narrador de la novela del siglo XIX, que recorre de manera exhaustiva los meandros argumentales del relato, definiendo, calificando, comentando, entrando y saliendo de todas las situaciones; penetra en el alma y el cuerpo de su protagonista, instala y desinstala el decorado teatral que lo envuelve, desmenuza los viajes que emprende, juzga, critica, evalúa, echa pie atrás, se burla y se compadece, se prosterna y lo abofetea, visita junto a él las ciudades que lo acogen o asedian; lleva al receptor de la mano, lo interpela, dialoga con el desocupado, con el amable, con el hipócrita lector, lo pasea, le recuerda datos, nombres, sucesos, lo despista, lo vuelve a encaminar, en suma, ese intruso inevitable, como llama Vargas Llosa al narrador de cualquier relato, rompe la dimensión actual de la novela contemporánea, aquella de una voz fría, lejana e impersonal, para agarrarnos de las solapas y no soltarnos, para recordarnos que estamos en presencia de una obra literaria, pero también para decirnos que la ficción reordena aquello que en la vida es azaroso y no manejamos. Esa figura, ficticia según los profesores de literatura, es el puente entre Joaquín y él, el sobrino escritor, su exégeta, y entre Joaquín y los lectores. 
Nunca este narrador, tan parecido a Jorge Edwards, tan parecido como que se llama igual y vive en la misma casa y calle donde él vive, además en la misma ciudad y en el mismo país, adopta frente a Joaquín una actitud distante, ni siquiera objetiva; con frecuencia lo desprecia, lo homenajea, hace de él, al mismo tiempo, el panegírico y la diatriba, no le escribe un soneto elegíaco, ya que no hay muerto malo, sino que lo moviliza a través de una escritura apegada al delirio, puñados de palabras arrojados sobre un tinglado de teatro, de farsa, de tragicomedia, precario y seductor, donde el tío Joaquín es a la vez Hamlet y Segismundo, Otelo y Macbeth, Don Juan y el jugador de Dostoievski.

Jorge Edwards crea en su novela una escenografía, una puesta en escena, ambienta las numerosas acciones de su historia con diversos telones de fondo, los decorados intercambiables que encuadran los movimientos de Joaquín. Construye una voz, en absoluto monocorde, más bien plagada de matices, contradictoria, engolada a veces, solemne, socarrona, sentenciosa en otros episodios; son los registros heterogéneos de la voz narrativa que expresan al personaje y su circunstancia: un narrador en tercera, coincidente con el autor real, Jorge Edwards, el mismo que apostrofa a cada rato a Joaquín, enjuiciándolo, exaltándolo, descolocándolo. En medio de esta rica perspectiva sería fácil perderse, ¿quién habla en cada circunstancia? Un intento de respuesta es: la misma voz metamorfoseada. Al sobrino lo salva, y de qué manera, su arte de novelar y en especial el uso de la amenidad como virtud, como estructura narrativa. Es imposible cansarse, dejar caer el libro de las manos, el lector informado conoce el desenlace pero no sabe cómo va a sobrevenir.

\section{La oscura vida radiante}

Tras sus viajes a París, siguiendo la ruta planteada por Rubén Darío, puesto hace rato el traje de petimetre afrancesado, Joaquín esquiva con éxito la sífilis y la tuberculosis, los modos de morir en aquel tiempo, pero sucumbe a la parisitis y la complementa con su huida, en 1910, para el centenario de Chile, a Río de Janeiro, tras el escándalo suscitado en la sociedad criolla luego de la publicación de El Inútil. Cabe hacer notar que Alberto Fuguet no alcanzó algo semejante con Mala Onda durante los ochenta. Joaquín escribe un libro de viajes (Tres Meses en Río de Janeiro) sobre su insólita experiencia carioca. Por su parte, la novela El Inútil es comentada con furia por el crítico oficial, Omer Emeth, de El Mercurio. El sacerdote la objeta en términos éticos, morales, le da con un fierro y se ensaña con su desesperanza, con su cinismo disfrazado de escepticismo, 
con su ateísmo, no obstante ser su autor un devoto de la Virgen María, un mariano sin redención. ¡Es lo peor de lo peori, exclama el cura. Años después un poeta desaforado, Pablo de Rokha, gritará lo mismo, pero denostando a los evaluadores literarios: ¡En Chile todos los críticos son curas!

Joaquín va a París a corromperse un poco más, a seguir quimeras voluptuosas tras una cocotte; sus piernas y su cuerpo todavía son ágiles y corre en busca del enigma de la Bella Otero, una arcangélica bailarina española; se sitúa de lleno en la etapa de gran señor, el que se da la gran vida, aunque no le queda muy claro cómo o quién financia todo aquello, vagas y sustanciosas herencias, un paquete de acciones, tierras, propiedades que aparecían en el momento más oportuno y lo salvaban del naufragio de verse obligado a trabajar estúpidamente para vivir, del destino de suche, de la órbita del medio pelo, de transformarse en empleado de alguna repartición ministerial, sometido a un horario, a jerarquías, a jefes, a un sueldo, a vacaciones mezquinas, a la sombra de las administraciones, según el poema "Desespediente", de Neruda.

No obstante, y nos lo señala la novela El Inútil de la Familia, Joaquín tiene alguna relación, por periférica que sea, con la diplomacia, con los escalafones, con los funcionarios de carrera y los advenedizos, con las pugnas del pequeño poder, pero logra salir a flote sin claudicar del todo y se reconoce a sí mismo, por encima de cualquier acecho, como un escritor, un cronista, el tábano de la vida chilena, nuestro más grande reprendedor, como lo llamó la Mistral.

Sin embargo aún están lejos, lejísimos, los años de la vida pichiruche, cuando se trasladará a residir junto a los dos hijos que tuvo con su primera esposa, la española Ángeles, la granadina, la mujer que nunca se ambientó del todo en el horroroso Chile, a la calle San Diego. Su mapa domiciliario tiene, no obstante, aún otras estaciones. ¡Dónde vinimos a parari, tal vez habrá comentado el extravagante padre y esposo en segundas nupcias —o náuseas según el decir popular—, desposado en la madurez con Mayita, ante la lejanía de su casa ubicada en Santo Domingo, su última residencia terrestre, cerca de Catedral, de Compañía, otrora barrios principales, en los años sesenta en la plenitud de su decadencia, sectores urbanos llenos de casas de adobe con revestimientos de arquitecturas nobles, neoclásicas, decimonónicas, nostálgicas mansiones transformadas en casas de huéspedes, en hoteles para vendedores viajeros provincianos, con tejados donde se refugian y orinan gatos melancólicos, con muros que soportan la presión de parejas turbias y borrachos lunáticos.

Si bien Edwards Bello nació en 1887, es, a pesar de sus rémoras de señor victoriano transformado en caballero chileno, más bien un hombre del 
siglo XX; de acuerdo a esa condición aparecen en la novela del sobrino, en primer lugar y de manera breve, los principales hechos históricos de los que fue contemporáneo el tío: la revolución parlamentaria de 1891, Balmaceda, apodado el Champudo, el Presidente Zamacueca, el Anticristo; luego la matanza de la escuela Santa María de Iquique, en 1907; el surgimiento de Arturo Alessandri, el León de Tarapacá, el tribuno liberal, el gran demagogo y macuco de la política chilena, y su opuesto el coronel Ibáñez, el Caballo; un león y un equino se disputan a las masas. Joaquín sucumbe por poco tiempo a la tentación autoritaria, se dice que, años después, tiene una foto de Hitler en su velador, pero son novelerías, cuentos alucinados; después de la dictadura de Ibáñez, de 1927 a 1931, surge la efímera República Socialista de Marmaduque Grove, el que decía mandar el buque, don Marma, el piloto enloquecido del avión rojo, que voló desde Argentina a Concepción para desatar la oleada insurreccional que tomaría por asalto el cielito lindo y de paso, en un vuelo rasante, el palacio de gobierno; Grove, el político idealista y de buenas intenciones que abre la puerta, sin desearlo, a la farsa, el orador con voz de cureña; es época de relegados a la Isla de Pascua, de pasiones, de defenestramientos de prohombres y ministros, de muchachas con principio de tisis, de tranvías, de adolescentes con boinas grises y corazones en calma.

A continuación irrumpe en la novela de Jorge Edwards el Frente Popular, Pedro Aguirre Cerda, el terremoto del 39, en Chillán, las elecciones, las alucinaciones, Joaquín denuncia el arribismo, se siente satisfecho, a pesar de los pesares, de haber roto con los siúticos, o pisiúticos, según el rescate de palabras anacrónicas que Jorge Edwards con frecuencia emprende en sus novelas, y en ésta aún más, auxiliado, como nos lo dice con su tono coloquial, de cercanía, de conversación entre amigos, por el diccionario de chilenismos de don Zorobabel Rodríguez (en aquellos años joaquinescos era posible llamarse Zorobabel); si aparecen granos y pústulas en la cara de algún personaje habla de lamparones; si se trata de la estampa empaquetada de un hombre es un gomoso; si se refiere a un homosexual es un maricantunga; si alguien se roba algo, lo guachipea.

Joaquín sigue escribiendo sus crónicas por cientos, llegan a miles, todos los jueves en La Nación, pero no olvida componer sus novelas, aparece La Chica del Crillón (1935), y ese itinerario nos lo devela su sobrino Jorge a través de El Inútil de la Familia, un relato fluvial, en expansión, desbordado, circular, que a veces vuelve atrás y nos lo advierte y recuerda, que se inicia con la apuesta fallida de Edwards Bello a un caballo, "Forastero”, en el Hipódromo Chile, del barrio La Palma, pero el jugador se equivocó y le puso todo su dinero al que llega placé, a "Lucky Jim”; ahí se abre un 
enorme paréntesis, semejante a un abismo, por el que discurre la novela que estamos leyendo; a Joaquín le sobreviene el ataque, se desploma. Comienza el relato de su historia.

Todos los personajes creados por Joaquín son máscaras suyas, él es la persona dramática, como Unamuno, como Pirandello, en busca de sus personajes, aún la protagonista de La Chica del Crillón es Joaquín, levemente travestido. Él es Eduardo Brisset Lacerda, el personaje de El Inútil, también Pedro Plaza, de Criollos en París, y Pedro Wallace, de El Chileno en Madrid. Por otro lado, redacta una y mil veces su novela, su gran novela, Valparaíso, Ciudad del Viento, donde su autor es el eje del mundo; la bautiza de diversos modos, le quita elementos al título, a la historia, muy parecida a una gran crónica porteña, a un grabado tan nostálgico como agudo; termina, después de pasar por rótulos como "En el Viejo Almendral", por dejarle el de "Valparaíso, fantasmas" hasta llegar al actual, "Valparaíso", sin más. Ahí acierta un pleno, no el del vértigo de los números rojinegros de la ruleta, sino el de una ciudad puerto que fue siempre el marco más adecuado para un hombre como él, una sombra, llena de sonido y de furia, pero sombra al fin.

\section{Apariciones y desapariciones}

Por uno de los vericuetos de la novela de Jorge Edwards, aparece, de modo picaresco, un genio social, Jorge Cuevas Bartholin, en el Santiago de las décadas del veinte y del treinta un don nadie, un NN que termina por casarse con una millonaria, Margaret Strong Rockefeller, y compra un marquesado, el de Piedrablanca de Guana. Se transforma en el Marqués de Cuevas, en Europa nadie conoce el dejo algo ridículo del apellido que suele designar la suerte absoluta, la tremenda cueva, la del Milodón, la de Altamira, la suerte total. Jorge Cuevas, el gran cuevudo, se vuelve un magnate, un diletante, un productor, un manager — como años antes Diaghilev con Nijinski-, del famoso ballet del Marqués de Cuevas, esplendoroso en la década del cincuenta. Cuevas, Cuevitas en la etapa previa y subdesarrollada de su residencia en Chile, es el organizador de eventos antológicos como el gran baile de Biarritz, es él quien le muestra a Joaquín una estela que el escritor no seguirá jamás: la del triunfo, la del éxito, la del encanto social. Basta ya de derrotas, de fracasos, de tumbos, de pérdidas.

En este sentido, Joaquín obtuvo dos grandes reconocimientos a su tarea como escriba, sólo igualado por otro bohemio y solitario, Daniel de la Vega, los premios Nacionales de Literatura (1943) y de Periodismo (1955), aunque en aquellos años consistían en recompensas monetarias mezquinas 
que se entregaban sólo una vez y excluían, como ahora, una renta vitalicia; por lo tanto, se fueron como vinieron, veloces.

Mientras tanto, su padre, siendo el retoño aún joven, le regaló una pistola marca Colt, entre tantos significados, símbolo de autoridad patriarcal. Debe usarla para defenderse, ¿de quién?, de rufianes que lo esperan cuando emerge de madrugada, balanceándose por los whiskies ingeridos tras una noche de invierno en un garito, chispeante porque viene con los bolsillos llenos, pero eso rara vez ocurrió ya que salía con la corbata de mariposa marchita, con la ropa impregnada de humo, perdedor, decepcionado y jurando que no volvería a ingresar a esos tugurios llenos de bribones.

El ataque cerebral que le sobrevino en la madurez va a acelerar el deseo de usar el revólver Colt. Importa decir que en su juventud protagonizó, junto a un amigo, un suicidio frustrado, ambiguo, parecido a un duelo, más cerca del absurdo que del deseo de autoeliminación. Su cara recogida, la parálisis de un lado de su cuerpo, la trabajosa e inalcanzable rehabilitación, la dependencia de Mayita, su segunda esposa, el báculo de su vejez, lo convencen de no dejarse vapulear más.

Lo ataca la vanidad postrera, la peor, la del epílogo, la que se niega a aceptar la llegada de la vejez; en la remota página de una crónica habló de la tragedia de la fealdad sin gracia, jél, el esteta que contempló el esplendor carnal de adolescentes que se le dieron maniatadas! Cuando debía tomarse una foto para la solapa o la contratapa de las ediciones que preparaba Alfonso Calderón de sus crónicas, sufría para que no se le notara la papada. Entonces ensaya en el aire posiciones para gatillar la pistola con su brazo en buen estado, disparos imaginarios, filigranas macabras que no se borran al instante en la atmósfera del cuarto y permanecen en su memoria. Él las espanta con su brazo sano para que no las vea la Mayita cuando entre a su cuarto para llevarle la comida, el té, para encenderle la televisión, para atenderlo.

El cuerpo y el alma sucumbieron con más pena que gloria, si bien no se han envilecido; el cerebro sigue intacto, llegaron sin ser invitados la corpulencia de la madurez, el cansancio, la decrepitud, muy luego sobrevendrá la putrefacción, debe soportar día a día barquinazos que se confabulan para agredirlo, domesticidades recurrentes, conflictos innobles, cuentas que se arrastran, tiene un enemigo en su interior que le tiende celadas a cada paso y lo impulsa a usar el arma de fuego para defenderse de sí mismo. Él es el enemigo que lo acecha mientras arrastra sus pies empantuflados por el parquet de la vieja casa, incapaz de recordar sus pasos de danza en los salones europeos, las sevillanas de tarjeta postal que bailaba bajo las lámparas de lágrimas, su estampa fosforescente de marqués de Bradomín, de tránsfuga, de turista de lujo en transatlánticos. 
Se acerca el desenlace de la novela de Jorge Edwards, el momento de comprobar si la ficción novelesca supera a la realidad o sucede lo contrario, de cotejar con la imaginación del sobrino novelista lo que no está del todo documentado respecto de la vida del tío. A lo lejos yace Valparaíso, el puerto que siempre aguarda; Joaquín está en el "Bar Inglés”, mientras merodean por el plan otros fantasmas; María Luisa Bombal anota en una agenda obsoleta impresiones para una novela que jamás escribirá; Carlos León juega ajedrez solo en el café Riquet; Carlos Pezoa Véliz cojea al ingresar al ascensor Polanco.

El Inútil de la Familia puede ser además la crónica rigurosa y a la vez desopilante de dos escritores, ¿separados por un idioma común?; también la escritura de dos literatos equidistantes por tiempos, por sensibilidades, por estilos, por visiones de mundo diferentes, pero no enemigas, que entran a veces en la misma órbita, quizás sin buscarlo, tal vez a pesar de ambos. Hay en la novela capítulos excepcionales, el I, el XXII, el XXV, el XXXII, el XXXV, también uno que consideramos prescindible, el XXIV, donde Jorge Edwards relata una parte de su permanencia en Cuba a cargo de la misión de abrir la embajada de Chile en la isla caribeña, a propósito del objetivo revolucionario planteado por el gobierno de Salvador Allende, en los años setenta. Otras voces, otros ámbitos.

En medio de las crisis y de las tragedias eternas de Chile, el Flandes Indiano, la Ínsula Barataria, el Horroroso Chile, el limbo ajeno al mundo, donde la nacionalidad cuando es consultada, en Europa por ejemplo, produce estupor: ¿'es una nacionalidad o una enfermedad?, ¿'es posible ser chileno?, en esta circunstancia poco grata para un artista, para un escritor, un hombre huraño, con la maleta del regreso dispuesta, se detenía a mirarnos a través del prisma de papel de sus novelas y de sus crónicas, a cuestionarnos, a decirnos que aún podemos ser menos malos, menos chaqueteros y apocados, o, sin más, ser mejores. En su habitación tecleaba una máquina de escribir para llegar el próximo jueves a la redacción del diario con sus hojas mecanografiadas. Unos años después, su sobrino lanza signos sobre la pantalla de un computador para rescatar al tío del olvido, de la venenosa memoria. Uno fue el perseguidor del otro, lo siguió, quizás sin proponérselo pero sin poder evitarlo, fue su virtual biógrafo, su cancerbero, su panegirista y su difamador, quien se ofreció para desenterrarlo, por medio de un largo relato, de palabras impresas sobre cuartillas, naderías referentes a siluetas en negro, el sobrino remoto se dispuso a exhumar su cadáver, a limpiar la sangre de su cara, a tapar el cuerpo con las hojas de su novela.

El tío Joaquín, el enojón, nos reprendía, nos tiraba las orejas, se burlaba de nosotros por apequenados, o nos ironizaba para que no 
nos apequenáramos, el sobrino Jorge elaboraba una escritura sobre el otro - también una escritura relativa a otra escritura—, una narración en torno a su doble escritor, sobre mi prójimo, mi espejo, yo-él, yo es otro, el pariente pobre, temido y admirado, la silueta intercambiable con la suya para que ambos hicieran una sola sombra larga, como en el Nocturno, de José Asunción Silva.

"Ni el tiro del final te va a salir", dice el tango, por fortuna a Joaquín le salió perfecto y certero en su boca, el 19 de febrero de 1968. Un estampido que hizo volar a las palomas del tejado en la casa de calle Santo Domingo, un balazo que le dio el descanso anhelado y que, momentáneamente, interrumpió el orden de las familias. 